\title{
Erratum to: Amplitude-oriented exercise in Parkinson's disease: a randomized study comparing LSVT-BIG and a short training protocol
}

\author{
Georg Ebersbach • Ute Grust • Almut Ebersbach • \\ Brigitte Wegner · Florin Gandor • Andrea A. Kühn
}

Published online: 3 July 2014

(C) Springer-Verlag Wien 2014

\section{Erratum to: J Neural Transm}

\section{DOI 10.1007/s00702-014-1245-8}

In the online version of the original article, Fig. 1 was incorrect. The correct version is given below.

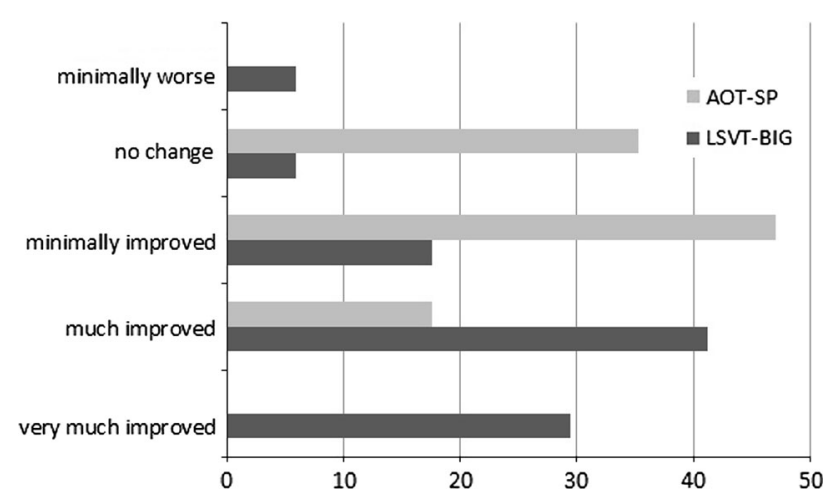

Fig. 1 Patients clinical global impression of change from baseline to week 16 (in percent). LSVT-BIG standard protocol, AOT-SP amplitude oriented training short protocol

The online version of the original article can be found under doi:10.1007/s00702-014-1245-8.

G. Ebersbach $(\bowtie) \cdot$ U. Grust · A. Ebersbach · F. Gandor Fachkrankenhaus für Bewegungsstörungen/Parkinson, Paracelsusring 6a, 14547 Beelitz-Heilstätten, Germany e-mail: ebersbach@parkinson-beelitz.de

\section{B. Wegner}

Institute of Medical Biometrics and Clinical Epidemiology, Charité University Medicine, Berlin, Germany

A. A. Kühn

Department of Neurology, Charité University Medicine Berlin, Campus Virchow, Berlin, Germany 